\title{
Tausende Franken sparen im BVG
}

Überprüfen Sie jetzt Ihre berufliche Vorsorge!

\section{Enorme Unterschiede}

Die Unterschiede im Preis-Leistungs-Verhältnis der verschiedenen Anbieter sind riesig. Vor allem folgende Punkte müssen beachtet werden:

- Höhe der Verwaltungskosten und der Risikobeiträge;

- Verzinsung des Altersguthabens im obligatorischen und im überobligatorischen Bereich;

- Rentenumwandlungssatz.

\section{Vergleichen lohnt sich!}

Wie Sie im folgenden Beispiel sehen, lohnt sich die kostenlose und unverbindliche Überprüfung Ihrer beruflichen Vorsorge durch einen Berater FMH Insurance Services:

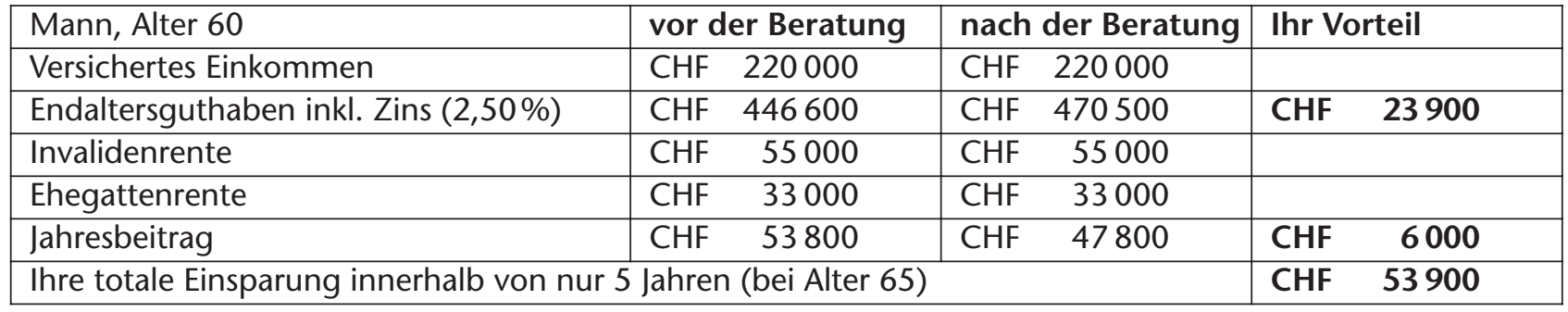

\section{Kündigungsfrist: Stichtag 30. Juni 2007!}

Viele Vorsorgeverträge können nur unter Einhaltung einer Kündigungsfrist von 6 Monaten auf Ende Jahr gekündigt werden. Retournieren Sie den untenstehenden Talon deshalb noch heute, damit wir Ihre bestehenden Verträge überprüfen und Ihnen eine Offerte unterbreiten können.

\section{Profitieren Sie von unserem Angebot}

Ihre Bedürfnisse stehen bei uns im Mittelpunkt. Mit unserem Namen garantieren wir Ihnen die Betreuung durch professionelle Berater mit langjähriger Erfahrung im Versicherungs- und Bankenbereich. Dank unserer Unabhängigkeit können wir Ihnen das für Sie am besten geeignete Produkt anbieten.

\section{Antworttalon}

Vorname / Name

Adresse

PLZ / Ort

\section{Geburtsdatum}

Telefon privat/Geschäft

Beste Zeit für einen Anruf

E-Mail-Adresse

Ich wünsche eine persönliche BVG-Beratung (bitte Kopie des Pensionskassenausweises beilegen).

I Ich interessiere mich für:

\begin{tabular}{ll} 
Pensionsplanung & Krankenkasse \\
Säule $3 a$ & O Rechtsschutzversicherung \\
O Finanz-/Steuerplanung & O Berufshaftpflichtversicherung \\
\hline
\end{tabular}

\section{GFMH INSURANCE}

Roth Gygax \& Partner AG = Koordinationsstelle Moosstrasse 2 『 3073 Gümligen

Telefon 0319595000 \&ax 0319595010 mail@fmhinsurance.ch $\square$ www.fmhinsurance.ch 